\title{
Analysis of Factors Affecting Freight Demand Based on Input-Output Model
}

\author{
Changxiang Lu $(\mathbb{D}$, Shaochuan Fu, Jiaqi Fang, Jikai Huang $\mathbb{D}$, and Yong Ye $\mathbb{1}$ \\ School of Economics and Management, Beijing Jiaotong University, Beijing 100000, China \\ Correspondence should be addressed to Yong Ye; yong_ye@foxmail.com
}

Received 18 January 2021; Revised 1 March 2021; Accepted 9 March 2021; Published 31 March 2021

Academic Editor: Arunava Majumder

Copyright (c) 2021 Changxiang Lu et al. This is an open access article distributed under the Creative Commons Attribution License, which permits unrestricted use, distribution, and reproduction in any medium, provided the original work is properly cited.

Freight demand is a highly variable process over economic and industrial structure, and accurate freight demand forecasting is the basis of transportation planning. In order to clarify the influencing factors of freight volume so as to analyze and predict the change trend of freight volume accurately, this paper analyzes the impact of changes in economic, industrial structure, and complete consumption coefficients on freight demand, through constructing an input-output model for transportation value analysis and forecasting freight volume by fitting data of transportation value and freight traffic. Studies have shown that the growth in economic aggregate is the main reason for the increase in the value of transportation, and the change in the complete consumption coefficient is the main reason for the increase in freight traffic.

\section{Introduction}

Freight demand forecasting is the basis of transportation planning. The wrong forecast of freight demand may lead to the advanced construction of transportation and waste of resources, such as Japan in the 1980s, or cause the delayed construction and the loss of freight transportation congestion, such as Iraq in the 1970s. Therefore, freight demand forecasting has aroused the interest of the transportation sector and many scholars. This paper attempts to describe and analyze the driving factors that affect China's freight demand in order to better study the future development trend of freight.

In the past, researchers believed that there was a linear relationship between freight transportation demand and GDP [1-3]. The nature of the industry, such as the proportions of primary, secondary, and tertiary industries, has different effects on freight intensity [4]. Alises and Vassallo [5] show that the economic elasticity of freight transportation is gradually decreasing. However, Zhang et al. [6] believe that economic factors are still the main factors affecting freight volume. Wang et al. [7] believe that freight volume is affected by macroeconomics, industrial structure, and supply capacity. The research of Sun et al. [8] shows that resource and population distribution and investment in fixed assets are the main factors influencing railway freight volume. In addition, supply chain management strategies will also affect freight volume, such as inventory management strategies [9-13] and replenishment strategies [14]. Previous studies have analyzed the influencing factors of freight volume from many aspects, but because of the lack of comparative analysis of influencing factors, the importance and relevance of influencing factors cannot be reflected.

Many research models are established, such as developing and applying transportation market shares models [15], transportation supply chain models [16], spatial accounting models [17], and multiple regression models [18]. However, such methods are found difficult to predict the growth of freight volume accurately due to the complexity of the economic system and the rapid development of the service economy.

Input-output (IO) analysis method was proposed by American economist Leontief in 1925. The input-output model can analyze and investigate the quantitative dependence relationship between the freight transportation sector and other sectors in the national economy $[19,20]$. The IO model captures the nature of interindustry interaction, has relatively low data requirements, and is easy to implement 
[21]. Based on the expression of intersectoral multiplier effects, the IO model allows us to describe the effects on the transport system caused by shocks in the economic system, both from a theoretical and an application point of view.

This paper considers an aggregate level of freight transportation, correlates the freight volume with the operation of the economic system, and then constructs the IO model. The model is structured on two levels: the first level forecasts the output value of the production department according to the exogenous demand and the second forecasts the tonnage of goods transported according to the relationship between the value of freight demand and freight volume in the economic system. Through the elaboration of time series of input-output tables for China, the model is validated and used to formulate forecasts for different future scenarios and then the influencing factors of freight traffic are analyzed.

This paper tries to answer the following two questions: (1) the relationship between economic development and transportation demand and (2) influencing factors of freight volume growth. The novel contribution of this paper is as follows: (1) the national freight volume was predicted by the input-output model. In order to reflect the impact of changes in industrial structure on freight volume better, this paper subdivides the industrial structure into 42 sectors, and the impact of 42 sectors on freight volume was analyzed, which is more specific than the previous division of the three industries; (2) comparative analysis of the influencing factors of freight value and freight volume was carried out through the complete decomposition model, and the influence degree of economic aggregate, industrial structure, and complete consumption coefficient on freight value and freight volume was obtained, so as to obtain the changing trend of freight volume accurately.

\section{Literature Review}

The literature related to this paper can be divided into three parts: (1) factors affecting freight demand, (2) input-output model, and (3) freight volume forecast.

2.1. Factors Affecting Freight Demand. Robert et al. [22] have identified and evaluated the factors of freight demand. Their research shows that population, economic activities, fuel prices, environment, and policies are the main influencing factors, among which GDP and GDP per capita are commonly used indicators of economic activity. Fite et al. [23] conducted regression analysis on 107 indexes related to freight volume and believed that the producer commodity price index of construction materials and equipment (PCPICM\&E) was the most relevant parameter. Agnolucci and Bonilla [24] conducted a study on the relationship between freight volume and GDP in the UK from 1956 to 2003. Their research found that the decoupling of freight volume and GDP accelerated, and the price and income elasticity also decreased to $18 \%$ and $65 \%$. Wang et al. [25] proposed a hierarchical model. The model shows that the demand for truck freight can be estimated by truck traffic, population, number of companies, and income. Short et al. [26] studied the relationship between Sweden's economic activities and freight volume. The study found that, in the short and medium term, changes in imports and exports led to large fluctuations in freight demand; in the long run, freight demand and GDP are coupled, and there is no sign of decoupling. Wijeweera et al. [27] studied the impact of freight prices, international trade, and business cycles on Australia's rail freight demand. Their study shows that the fluctuation of freight rates and the Australian dollar was the most important factor affecting Australian rail freight. Alises and Vassallo [28] studied the impact of economic growth, industrial structure, and road transport intensity on the demand for road freight. The results show that, overall, the growth of total road transport demand is mainly driven by economic activities. Patil and Sahu [29] used regression and time series models to estimate the freight demand of Mumbai ports. Their research concluded that GDP and crude oil production are the most important factors affecting freight. Wang et al. [30] analyzed the relationship between freight demand and economic development. They believe that China's overall economic development is decoupled from freight development, and the intensity of transportation is declining. Khan and Khan [31] analyzed the demand for rail freight in Pakistan. The study showed that GDP and freight are the two most important determinants of rail freight demand. Table 1 shows the comparison between some studies and this paper.

2.2. Input-Output Model. There are three main types of input-output models: inter-regional model-IRIO [54, 55], multiple model-MRIO [56], and multiregional econometrics model [57, 58]. Izard et al. [59] proposed an inter-regional input-output model, which introduced a trade coefficient, which represents the proportion of product $m$ produced and used in region $j$ used in the production and use of product $n$ in the region. Because the proportion of trade is difficult to estimate, Moses [60] simplified the calculation of the trade coefficient, considering only the trade flow and no longer the destination. The wrong estimation of the trade coefficient may cause a large deviation in the forecast of freight traffic, which requires multiple corrections [61]. Miller [62] gave a detailed application explanation of the input-output model and constructed a fitting model of transportation and economy. Voigtlaender [63] applied a dynamic input-output model to forecast freight demand in the United States. Rey [64] discussed the application of econometrics in the inputoutput table model and studied the alternative methods and models of the input-output model. Havenga and Simpson [65] used an economic input-output (I-O) model as a platform, supplemented by actual data, developed supply and demand data classified by space and sector, and converted the supply and demand of South African freight into a freight flow through a gravity model. The above literature has conducted a lot of research on the application of inputoutput models from the perspective of theory and practice and provided theoretical and methodological support for the research of this paper. 


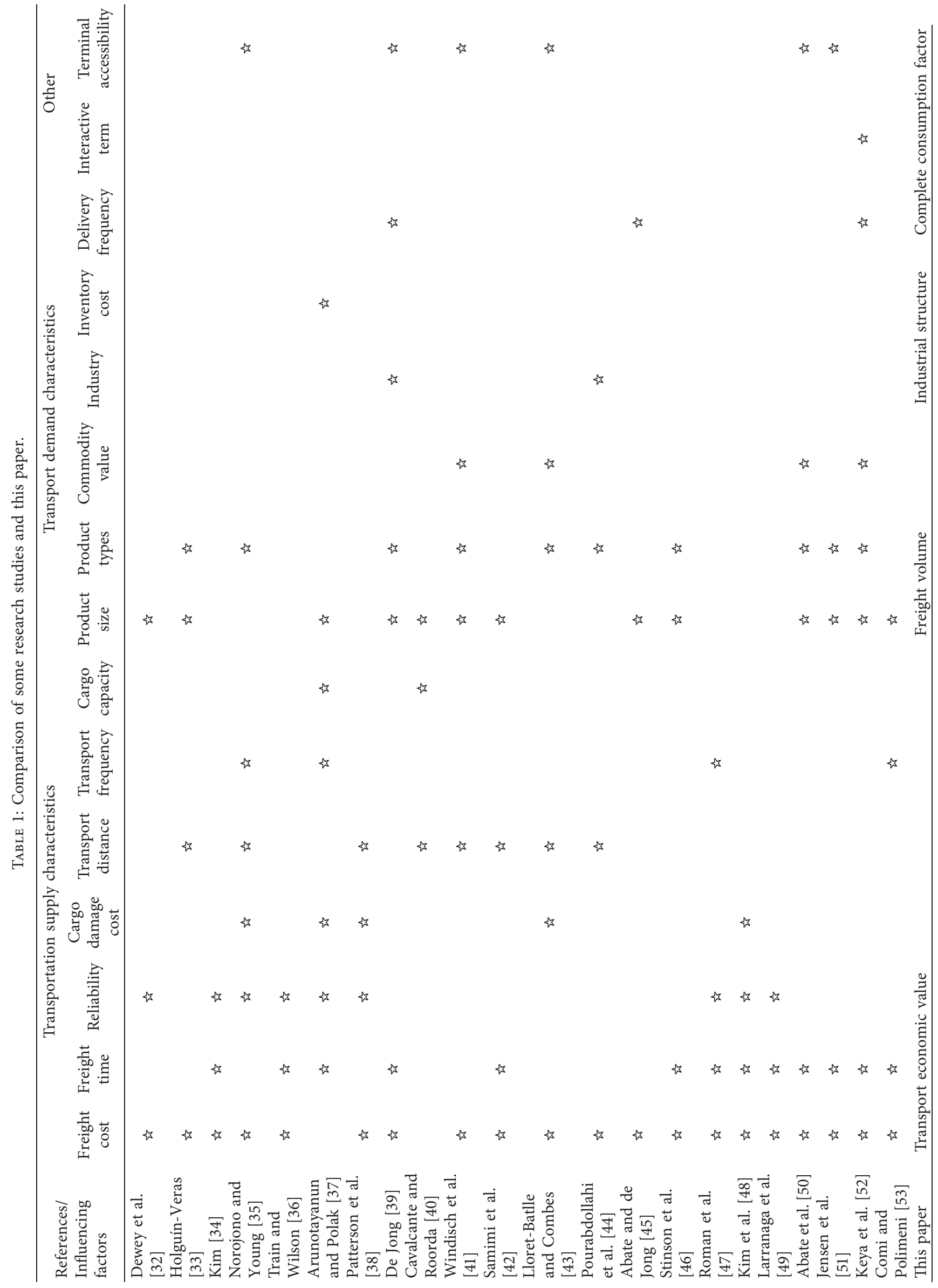


2.3. Forecast of Freight Traffic. Freight forecasting models can be grouped into five classes: the economic activity model, the four-step commodity model, the Origin-Destination (O-D) factoring method, the Flow Factoring Method (FFM), and the truck model. Many kinds of literature have used a variety of methods and models to predict freight volume from the national level, such as Daugherty [66], Picard and Nguyen [67], Mazzarino [68], and Regan and Garrido [69]. There are multiple measurement standards for freight traffic, and the common measurement standards are tons, ton-kilometers, and transportation costs (transportation costs or prices paid for transportation services). The accuracy of forecasting freight volume depends on the classification and aggregation of data and the estimated model [70, 71]. Among the influencing factors of freight demand, the most important influencing factors are consumer demand, production structure, and trade mode [72, 73]. Castro-Neto et al. [74] used the online support vector regression algorithm to predict the traffic flow of the road with good prediction accuracy. Chen [75] constructed a comprehensive transportation network, organically combined multiple transportation modes, and improved the accuracy of travel choice model prediction. Ahn et al. [76] combined Bayesian classifier and vector regression to predict the traffic demand of expressways and predicted and analyzed the expressway freight volume of Korea. Garrido and Mahmassani [77] developed a multinomial probit (MNP) model, which predicts freight volume based on time and space changes in transportation. Studies have shown that the model is more accurate. Pompigna and Mauro [78] used Italian economic data from 2000 to 2014 as the basis and used the macro-input-output method to analyze freight demand and forecasted Italian freight volume in 2027. The above research uses a variety of models and methods to forecast freight traffic. Generally speaking, national freight volume forecasting models are the integration of macroeconomic models.

\section{Problem Description and Modelling}

3.1. Model Description. The basic composition of the model is

(1) Direct consumption coefficient: the direct consumption coefficient refers to the value of the unit's total output of the $j$ th product sector directly consumed by the $i$ th product sector in the production process, usually recorded as $a_{i j}(i, j=1,2, \ldots, n)$. The formula of $a_{i j}$ is

$$
a_{i j}=\frac{x_{i j}}{X_{j}}
$$

where $x_{i j}$ represents the input amount provided by the $i$ th sector as an intermediate product to the $j$ th sector and $X_{j}$ represents the total investment of the $j$ th sector.

(2) Complete consumption coefficient: the complete consumption coefficient is the number of products completely consumed by the $j$ th sector when producing a unit product. It is called the complete consumption coefficient of the $j$ th sector for the first sector, usually denoted as $b_{i j}$. The complete consumption coefficient is the sum of direct consumption and all indirect consumption, and the calculation formula is

$$
b_{i j}=a_{i j}+\sum_{k=1}^{n} a_{k j} b_{j k} .
$$

The matrix formula is $B=A+B A$, and the formula for solving the complete consumption matrix can be obtained:

$$
B=(I-A)^{-1}-I
$$

(3) Balance formula: the input-output table has two important balance relationships, namely, row balance and column balance. Line balance: intermediate use + final use $=$ total output:

$$
\sum_{j=1}^{n} a_{i j} x_{i j}+Y_{i}=X_{i}, \quad i=1,2, \ldots, n,
$$

where $Y_{i}$ represents the final use amount provided by the $i$ th sector and $X_{i}$ represents the total output of the $i$ th sector.

Its matrix is expressed as $A X+Y=X$.

Column balance: initial investment + intermediate investment $=$ total investment:

$$
\sum_{i=1}^{n} x_{i j}+N_{j}=X_{j}, \quad j=1,2, \ldots, n,
$$

where $N_{j}$ represents the added value of the $j$ th sector.

3.2. Model Assumptions. The basis of the input-output theory is Walras' general equilibrium theory, which involves the following basic assumptions.

3.2.1. Homogeneity Assumption. Assume that each industrial sector produces only one homogeneous product. That is, the product is completely replaceable in this department but irreplaceable in other departments.

3.2.2. Proportionality Assumption. The input and output of the department are directly proportional, that is, there is a linear relationship between input and output.

3.2.3. Stability Assumption. The technology, production process, and management level are relatively stable.

3.3. Division of Departments. This paper uses the inputoutput tables compiled by China from 2002 to 2017 as the basic data. To facilitate model processing and analysis, the 135 departments, 149 departments, and 41 departments in 
different years have been uniformly adjusted to 42 departments. The specific divisions are shown in Table 2.

3.4. Decomposition of the Input-Output Model. According to the construction principle of the input-output table, the growth of transportation demand can be decomposed into three parts: increase in transportation demand caused by economic growth, industrial relevance and changes in production technology lead to the increase in transportation demand caused by changes in the complete consumption coefficient, and changes in transportation demand caused by the upgrading of industrial structure. Since the input-output table uses the value as the unit of measurement, the formula for calculating the economic value $Q$ of transportation can be expressed as

$$
Q=Z * X
$$

where $Z$ represents transportation intensity and $X$ represents the total output.

Taking the derivative of the above formula, we can obtain

$$
\partial Q=X \partial Z+Z \partial X
$$

Because $Z=(Q / X)=\left(\sum b_{j} X_{j} / X\right)=\sum b_{j} s_{j}$, where $b_{j}$ represents the complete consumption coefficient of each department for transportation, $X_{j}$ represents the total output of each department, and $s_{j}$ represents the proportion of each department's output to the total output.

The matrix of the above formula is expressed as $Z=B \times S$, where $B$ is the complete consumption coefficient matrix and $S$ is the structural variable.

Taking the derivative of formulas (3)-(8), we can obtain

$$
\partial Z=S \partial B+B \partial S \text {. }
$$

Putting formulas (8) and (9) into (7), we can obtain

$$
\partial Q=S X \partial B+X B \partial S+B S \partial X
$$

where $S X \partial B$ represents the changes in the transportation economy caused by changes in the complete consumption coefficient, $X B \partial S$ represents the changes in the transportation economy caused by changes in the industrial structure, and $B S \partial X$ represents the changes in the transportation economy caused by changes in the total economic scale.

In the time period $[0, t]$, the change of the economic value of transportation is

$$
\Delta Q=Q_{t}-Q_{0}=B_{t} S_{t} X_{t}-B_{0} S_{0} X_{0} .
$$

Let $B_{t}=B_{0}+\Delta B, S_{t}=S_{0}+\Delta S$, and $X_{t}=X_{0}+\Delta X$, and formula (11) can be expressed as follows:

$$
\begin{aligned}
\Delta Q= & Q_{t}-Q_{0}=\Delta B S_{0} X_{0}+B_{0} \Delta S X_{0} \\
& +B_{0} S_{0} \Delta X+B_{0} \Delta S \Delta X \\
& +\Delta B S_{0} \Delta X+\Delta B \Delta S X_{0}+\Delta B \Delta S \Delta X,
\end{aligned}
$$

with $Q=Z X=\sum b_{j} s_{j} X$, the demand for transportation value caused by different departments can be obtained as

$$
Q_{j}=b_{j} s_{j} X
$$

Let $b_{j t}=b_{j 0}+\Delta b_{j}, s_{j t}=s_{j 0}+\Delta s_{j}$, and $X_{t}=X_{0}+\Delta X$; then, in the period $[0, t]$, the changes in the economic value of transportation caused by different sectors are

$$
\begin{aligned}
\Delta Q_{j}= & Q_{j t}-Q_{j 0}=b_{j t} s_{j t} X_{t}-b_{j 0} s_{j 0} X_{0} \\
= & \Delta b_{j} s_{j 0} X_{0}+b_{j 0} \Delta s_{j} X_{0}+b_{j 0} s_{j 0} \Delta X \\
& +b_{j 0} \Delta s_{j} \Delta X+\Delta b_{j} s_{j 0} \Delta X+\Delta b_{j} \Delta s_{j} X_{0}+\Delta b_{j} \Delta s_{j} \Delta X .
\end{aligned}
$$

Combining the factors that cause the economic value of transportation into similar items and decomposing them according to the complete consumption coefficient change, industrial structure change, and total output change, the change in the economic value of transportation can be expressed as

$$
\begin{aligned}
\Delta Q_{j} & =b_{j q}+s_{j q}+X_{j q}, \\
b_{j q} & =\Delta b_{j} s_{j 0} \Delta X+\frac{1}{2}\left(\Delta b_{j} s_{j 0} \Delta X+\Delta b_{j} \Delta s_{j} X_{0}\right)+\frac{1}{3} \Delta b_{j} \Delta s_{j} \Delta X, \\
s_{j q} & =b_{j 0} \Delta s_{j} X_{0}+\frac{1}{2}\left(b_{j 0} \Delta s_{j} \Delta X+\Delta b_{j} \Delta s_{j} X_{0}\right)+\frac{1}{3} \Delta b_{j} \Delta s_{j} \Delta X, \\
X_{j q} & =b_{j 0} s_{j 0} \Delta X+\frac{1}{2}\left(b_{j 0} \Delta s_{j} \Delta X+\Delta b_{j} \Delta s_{j 0} \Delta X\right)+\frac{1}{3} \Delta b_{j} \Delta s_{j} \Delta X,
\end{aligned}
$$

where $b_{j q}, s_{j q}$, and $X_{j q}$, respectively, represent the impact of changes in the complete consumption coefficient, changes in industrial structure, and total output on the economic value of transportation.

\section{Algorithm}

4.1. Total Output Forecast. The total output of a department refers to the total value of all goods and services produced by the department in a certain period. To predict the total output of a department, you can first predict the added value of each department and then use the input-output model to calculate the total output of each department.

According to the column balance principle $A_{c} X+N=$ $X$ in the input-output table, the total output of the $i$ th sector can be calculated as

$$
X_{i}=\left(1-A_{c}\right)^{-1} \mathrm{GDP}_{i}, \quad i=1,2, \ldots, n .
$$

Because gray prediction is an exponential growth prediction, its prediction interval is trumpet-shaped, and the accuracy is poor in medium and long-term predictions. Therefore, to ensure the accuracy of the prediction, this paper adopts the equal-dimensional gray number recursive dynamic prediction method. The basic principle of this method [79] is that only one value is predicted at a time, and the predicted value is used to replace the first value of the original data sequence, keeping the same dimension and predicting one by one, which speeds up the convergence of the predicted value with high accuracy. From the verification 
TABLE 2: 42 sectors of the three industries.

\begin{tabular}{|c|c|}
\hline Numbering & Industry name \\
\hline 1 & Agriculture, forestry, animal husbandry, and fishery \\
\hline 2 & Coal mining and washing industry \\
\hline 3 & Oil and gas extraction industry \\
\hline 4 & Metal mining and dressing industry \\
\hline 5 & Nonmetallic minerals and other mining and dressing industries \\
\hline 6 & Food manufacturing and tobacco processing industry \\
\hline 7 & Textile industry \\
\hline 8 & Textile, clothing, shoes, hats, leather down, and its products' industry \\
\hline 9 & Wood processing and furniture manufacturing \\
\hline 10 & Papermaking, printing and cultural, educational, and sporting goods manufacturing \\
\hline 11 & Petroleum processing, coking, and nuclear fuel processing industry \\
\hline 12 & Chemical industry \\
\hline 13 & Nonmetallic mineral products' industry \\
\hline 14 & Metal smelting and rolling processing industry \\
\hline 15 & Metal products' industry \\
\hline 16 & General and special equipment manufacturing industry \\
\hline 17 & Transportation equipment manufacturing \\
\hline 18 & Electrical machinery and equipment manufacturing \\
\hline 19 & Communication equipment, computer, and other electronic equipment manufacturing \\
\hline 20 & Instrumentation and cultural office machinery manufacturing \\
\hline 21 & Crafts and other manufacturing \\
\hline 22 & Scrap \\
\hline 23 & Electricity and heat production and supply industry \\
\hline 24 & Gas production and supply industry \\
\hline 25 & Water production and supply industry \\
\hline 26 & Construction industry \\
\hline 27 & Transportation and storage industry \\
\hline 28 & Postal industry \\
\hline 29 & Information transmission, computer service, and software industry \\
\hline 30 & Wholesale and retail \\
\hline 31 & Accommodation and catering industry \\
\hline 32 & Financial industry \\
\hline 33 & Real estate \\
\hline 34 & Leasing and business services \\
\hline 35 & Research and rxperimental development \\
\hline 36 & Comprehensive technical service industry \\
\hline 37 & Water conservancy, environment, and public facilities management industry \\
\hline 38 & Resident services and other services \\
\hline 39 & Education \\
\hline 40 & Health, social security, and social welfare industries \\
\hline 41 & Culture, sports, and entertainment industry \\
\hline 42 & Public administration and Social Organization \\
\hline
\end{tabular}

Data source: National Bureau of Statistics of China.

results, the 7 -dimensional prediction overemphasizes the extension of the past trend, and the prediction is too high, the 5-dimensional prediction overemphasizes the extension of the recent trend, and the prediction is lower, and the 6dimensional prediction is more appropriate.

\subsection{Complete Consumption Coefficient Prediction. The RAS} method, also known as the biproportional scaling method, was proposed by Deming and Stephan [80] in 1940. The basic principle is to first assume that the input structure of the target year and the base year are the same. Under the control of the total output and intermediate use in the target year, use a set of row control vectors and a set of column control vectors to adjust the base year accordingly. Each row element and each column element of the direct consumption coefficient matrix in the input-output table makes the total calculated direct consumption coefficient equal to each control data. The mathematical expression of the RAS method is

$$
A_{t}=\widehat{R} A_{0} \widehat{S}
$$

where $A_{t}$ is the direct consumption coefficient matrix of the target year, $A_{0}$ is the direct consumption coefficient matrix of the base year, $\widehat{R}$ is the total row multiplier matrix, and $\widehat{S}$ is the total column multiplier matrix.

The total row multiplier matrix $\widehat{R}=\widehat{r}_{k} \widehat{r}_{k-1}, \ldots, \widehat{r}_{2} \widehat{r}_{1}$ can reflect the degree to which intermediate products are replaced by other products. Multiply $A_{0}$ by $\widehat{R}$ left: if an intermediate product in a row in $A_{0}$ is replaced by other products, all other intermediate products in this row will be 
replaced by other products to the same extent. The total column multiplier matrix $\widehat{S}=\widehat{s}_{1} \widehat{s}_{2}, \ldots, \widehat{s}_{l-1} \widehat{s}_{l}$ can reflect the degree of consumption of other departments by each department in the production process. Multiply $A_{0}$ by $\widehat{S}$ right: if the intermediate input of an intermediate product in a column of $A_{0}$ increases, the intermediate input of all other intermediate products in this column will increase by the same degree.

4.3. Economic Forecast. Assuming that the return to scale of the production function remains unchanged and according to the global economic growth model, it is estimated that China's total GDP as

$$
\mathrm{GDP}=\mathrm{TFP} \times K^{\alpha} \times L^{1-\alpha},
$$

where TFP represents total factor productivity, $K$ represents capital stock, $L$ represents the total labor force, and $\alpha$ represents the output elasticity of capital. According to the calculation of most scholars, $\alpha$ is 0.55 . According to the basic laws of world economic development, when an economy enters a capital surplus, the output elasticity of capital will gradually decrease, while the output elasticity of labor will slowly rise. Therefore, this paper assumes that the elasticity of capital-output will slowly decline from 0.6 in 2016 to 0.45 in 2035 and further to 0.4 in 2050 .

Step 1 (predict the total labor force): the formula is

$$
\ln P_{t}=\alpha \times \ln P_{t-1},
$$

where $P_{t}$ is the labor participation rate in year $t, P_{t-1}$ is the labor participation rate in the previous year in year $t$, and $\alpha$ is a constant parameter.

The labor participation rate refers to the ratio of the total employed population to the total population. Statistics from the National Bureau of Statistics of China show that, between 1995 and 2015, China's labor participation rate reached an average of about $56 \%$, and it was quite stable. Based on this, it can be assumed that, between 2020-2050, China's labor participation rate will also remain at around $56 \%$. The prediction results are shown in Table 3.

Step 2 (predict the capital stock): the formula is

$$
K_{\text {growth }}=\frac{K_{t}}{K_{t-1}}-1=\frac{I_{t-1}}{K_{t-1}}-6 \%,
$$

where $K_{\text {growth }}$ is the growth rate of capital stock, $I_{t-1}$ is the amount of capital investment in the previous year, and $6 \%$ represents the annual depreciation rate of capital. Since 2010, the growth rate of China's capital stock has been declining. The decline in capital growth may be due to the adjustment of the industrial structure. This paper predicts that, from 2021 to 2030, the average annual growth rate of capital is 7\%, from 2031 to 2040 , the average annual growth rate of capital is $5 \%$, and from 2041 to 2050, the average annual growth rate of capital is $3 \%$.
Step 3 (forecast total factor productivity): the formula is

$$
\mathrm{TFP}_{\text {growth }}=1.3 \%+\mathrm{CB}-\mathrm{FP},
$$

where $1.3 \%$ is the potential growth rate of TFP, CB represents the growth rate of inertial growth in emerging developing countries, and FP represents factors that hinder productivity growth from failure. The formula for inertial growth rate is

$$
\mathrm{CB}=c * 2.33 \% * \ln \left(\frac{\mathrm{TFP}_{\mathrm{USA}, t-1}}{\mathrm{TFP}_{i, t-1}}\right),
$$

where $2.33 \%$ is a parameter of development inertia, calculated from historical data, and $c$ is the national development speed parameter. The value is 1 for highgrowth countries, 0 for declining countries, and $c$ is between 0 and 1. Economic development itself has inertia, so this paper believes that China's economic growth inertia CB is about 0.3 .

The hindering factor FB formula is

$$
\mathrm{FB}=f * 1.8 \% \text {, }
$$

where $f$ is a hindering parameter, and its nature is opposite to $c$. It is 1 for declining countries and 0 for high-growth countries. Since China is an emerging developing country, the value of $f$ should be between 0 and 0.5 . Since 2006, China's total factor productivity has gradually declined. Total factor productivity is composed of human capital, $\mathrm{R} \& \mathrm{D}$ innovation, infrastructure, urbanization rate, and investment rate. Due to the aging of the population, the gradual improvement of infrastructure, and the decline in investment, the growth rate of TFP will continue to decline slowly in the future Trend [37]. Therefore, this paper predicts that the TFP growth rate will be $1.5 \%$ from 2021 to 2030 , $1.4 \%$ from 2031 to 4040 , and $1.3 \%$ from 2041 to 5050 .

In summary, under the baseline scenario, China's economic development will achieve an average annual growth rate of $4.8 \%$ from 2020 to 2035 and an average annual growth rate of $3.4 \%$ from 2036 to 2050 .

4.4. Industrial Structure Forecast. Use the gray system structure prediction method to predict the industrial structure in the input-output table. The calculation steps and methods are briefly described as follows.

Step 1: list the original data. Take the intermediate input data and intermediate output data of 42 industrial sectors in the 2002-2017 input-output table as the modeling sequence.

Step 2: establish a gray dynamic GM $(1,1)$ model for the above data series. The model can reflect $N$ related factors, and the equation of the gray state model is

$$
X_{1}=a X_{1}+u
$$

where $a$ represents the coordination coefficient between the variables. 
TABLE 3: China's total population and employment forecast (2020-2050).

\begin{tabular}{cccc}
\hline Year & Total population (unit: 100 million people) & Employment rate (unit: \%) & Number of employees (unit: 100 million people) \\
\hline 2015 & 13.6782 & 56.34 & 7.7063 \\
2020 & 14.0505 & 56.7 & 7.9666 \\
2030 & 14.3203 & 56.91 & 8.1497 \\
2040 & 13.8647 & 56.94 & 7.8946 \\
2050 & 12.7471 & 56.95 & 7.2595 \\
\hline
\end{tabular}

Note. The 2015 data comes from the National Bureau of Statistics of China, and the rest of the data are predicted by the author. Among them, the birth rate is assumed to be maintained at the level of 2019 , and the average life expectancy is 77 years.

Step 3: according to the above GM model group, list the system state equation matrix:

$$
\left[\begin{array}{c}
\dot{X}_{1} \\
\dot{X}_{2} \\
\vdots \\
\dot{X}_{n}
\end{array}\right]=\left[\begin{array}{llll}
a_{11} & & & \\
& a_{22} & & \\
& & \ddots & \\
& & & a_{n n}
\end{array}\right] \cdot\left[\begin{array}{c}
X_{1} \\
X_{2} \\
\vdots \\
X_{n}
\end{array}\right]+\left[\begin{array}{c}
u_{1} \\
u_{2} \\
\vdots \\
u_{n}
\end{array}\right],
$$

or it is written as

$$
\dot{X}=X+U
$$

Predict the main indicator values of each quadrant, and calculate the structure of the intermediate input and intermediate output, respectively.

Step 4: use the Runge-Kutta method to solve the system state equation.

Step 5: perform cumulative reduction on the solution results of the equation to obtain the fitted and predicted values of each factor in the system and analyze the results. If there is a deviation, the coefficient matrix can be adjusted, simulated, and analyzed step by step to achieve a better prediction effect.

\section{Model Construction and Forecasting}

5.1. Forecast and Analysis of the Economic Value of Transportation. Through the analysis of total output, industrial structure, and complete consumption coefficient, combined with the basic data of the input-output table from 2002 to 2017, the economic value of transportation in 2035 and 2050 can be predicted. The forecast data is shown in Tables 4 and 5 .

By 2035, the transportation value will be 696,538 trillion yuan. From 2017 to 2035, the average annual growth rate of the transportation value will be $7.25 \%$. By 2050, the transportation value will be 1,121,637 billion yuan, and the average annual growth rate of transportation value will be $3.23 \%$.

5.2. Regression Models. The difficulty of using the inputoutput model to analyze freight volume is to construct the functional relationship between value volume and freight traffic. Judging from the law of value volume and freight volume shown in the industrialization process of developed countries, the freight elasticity tends to gradually decrease, that is, the growth rate of freight volume is lower than that of value volume. The economic significance is that the tertiary industry develops faster in the middle and late stages of industrialization, while the growth rate of the primary and secondary industries that bring more freight demand has slowed, leading to a further slowdown in freight volume growth.

Based on the 2002-2017, input-output table and the statistical data of freight volume from the National Bureau of Statistics of China analyze the functional relationship between transportation value and freight traffic. The statistical data over the years is shown in Table 6.

We started regression analysis with one explanatory variable. Firstly, analyze the correlation between freight value and freight traffic. The Pearson correlation coefficient of the two is 0.977 , and the significance test probability is 0.01 . The analysis shows that the correlation between the two is significant, and predictive analysis can be performed. Secondly, to predict freight traffic, it is necessary to perform a regression analysis on freight value and freight traffic. Regression analysis refers to the statistical method of quantitative analysis of the interdependence between two or more variables. According to the relationship between the independent variable and the dependent variable, it can be divided into linear regression analysis and nonlinear regression analysis. Nonlinear regression includes power function and logarithmic function.

Given the characteristics of the growth rate of freight traffic, the quadratic function, cubic function, compound function, exponential function, logistic function, and $s$ function are excluded because the predicted values of these models are too high or too low. Based on the relationship between freight value and freight volume from 2002 to 2017, this paper uses the freight value as an independent variable and freight volume as a dependent variable to construct onevariable linear, power, and logarithmic functions. The fitting effect and prediction are shown in Table 7.

Although the linear regression model and power regression model have higher $R^{2}$, the logarithmic model also has good $R^{2}$. In recent decades, the freight economic elasticity of the United States, Germany, and other major developed countries has shown a trend of " $\cap$ " shape. Considering that China is about to enter the postindustrialization period and the growth law of freight volume in developed countries, the prediction effect of the logarithmic function is better. Based on the forecast of the logarithmic function (M1), China's freight volume in 2035 will be 64.485 billion tons and the freight volume in 2050 will be 72.518 billion tons. In 2017-2035, freight volume will achieve 
TABLE 4: Forecast the value of each Industry's demand for transportation in 2035.

\begin{tabular}{|c|c|c|c|c|}
\hline Industry number & $\begin{array}{c}\text { Total output } \\
\text { (unit: ten thousand yuan) }\end{array}$ & $\begin{array}{l}\text { Complete consumption } \\
\text { coefficient for transportation }\end{array}$ & $\begin{array}{l}\text { Value of demand for transportation } \\
\text { (unit: ten thousand yuan) }\end{array}$ & Percentage (\%) \\
\hline 1 & 1694385607.67158 & 0.0954 & 161562882.649893 & 2.32 \\
\hline 2 & 298638845.719085 & 0.0575 & 17175036.81653 & 0.25 \\
\hline 3 & 229301196.836365 & 0.0395 & 9049175.65735843 & 0.13 \\
\hline 4 & 129307146.775368 & 0.0501 & 6484079.06508876 & 0.09 \\
\hline 5 & 211843472.6172 & 0.1060 & 22453457.2200924 & 0.32 \\
\hline 6 & 3228474316.22645 & 0.1053 & 340105785.712392 & 4.88 \\
\hline 7 & 853635246.66695 & 0.1376 & 117422343.628579 & 1.69 \\
\hline 8 & 841006714.602347 & 0.1546 & 129998582.75392 & 1.87 \\
\hline 9 & 609580270.115972 & 0.1214 & 74024374.9193083 & 1.06 \\
\hline 10 & 890071738.040242 & 0.1254 & 111632630.312471 & 1.60 \\
\hline 11 & 798728493.815842 & 0.1063 & 84897524.7620998 & 1.22 \\
\hline 12 & 4039139792.04284 & 0.1386 & 559648454.680745 & 8.03 \\
\hline 13 & 1880344512.12754 & 0.1396 & 262428339.838558 & 3.77 \\
\hline 14 & 2504229609.09318 & 0.1066 & 266973521.479866 & 3.83 \\
\hline 15 & 1065158416.30454 & 0.1155 & 123006525.792954 & 1.77 \\
\hline 16 & 1682978234.46036 & 0.1205 & 202876346.366929 & 2.91 \\
\hline 17 & 2429683947.14023 & 0.1271 & 308797754.667791 & 4.43 \\
\hline 18 & 1370308888.66753 & 0.1164 & 159468719.375415 & 2.29 \\
\hline 19 & 2612610892.33714 & 0.1040 & 271783708.552732 & 3.90 \\
\hline 20 & 196602250.581008 & 0.1068 & 20990293.5368699 & 0.30 \\
\hline 21 & 59787097.2414924 & 0.1322 & 7903185.38635047 & 0.11 \\
\hline 22 & 136893612.608903 & 0.0673 & 9218409.26425335 & 0.13 \\
\hline 23 & 1297190651.07111 & 0.0907 & 117675194.364156 & 1.69 \\
\hline 24 & 159510145.246247 & 0.0904 & 14424819.0449973 & 0.21 \\
\hline 25 & 54399953.1939841 & 0.0700 & 3806428.68705191 & 0.05 \\
\hline 26 & 5957189642.43866 & 0.1190 & 709202296.350219 & 10.18 \\
\hline 27 & 3161032372.82554 & 0.1779 & 562210630.028183 & 8.07 \\
\hline 28 & 367581961.218591 & 0.2333 & 85768156.9498018 & 1.23 \\
\hline 29 & 2214431048.31268 & 0.0716 & 158565802.762279 & 2.28 \\
\hline 30 & 3292349264.93366 & 0.0798 & 262858124.788314 & 3.77 \\
\hline 31 & 1035351065.40907 & 0.0949 & 98272095.2840489 & 1.41 \\
\hline 32 & 4251929683.41493 & 0.0642 & 272915377.438803 & 3.92 \\
\hline 33 & 2815285849.95493 & 0.0470 & 132374469.392868 & 1.90 \\
\hline 34 & 3206746606.76096 & 0.1609 & 515839451.13986 & 7.41 \\
\hline 35 & 377897718.800984 & 0.1301 & 49152590.0449114 & 0.71 \\
\hline 36 & 1602255760.98183 & 0.1285 & 205911785.908507 & 2.96 \\
\hline 37 & 364681798.109706 & 0.1080 & 39389822.0622763 & 0.57 \\
\hline 38 & 774785377.775754 & 0.0624 & 48379471.9241988 & 0.69 \\
\hline 39 & 1060080189.38893 & 0.0458 & 48525487.4586229 & 0.70 \\
\hline 40 & 1375216767.21162 & 0.0961 & 132192061.925051 & 1.90 \\
\hline 41 & 482313945.881959 & 0.1049 & 50578115.6117033 & 0.73 \\
\hline 42 & 1938419823.08232 & 0.0977 & 189436875.490029 & 2.72 \\
\hline
\end{tabular}

an average annual growth rate of $1.65 \%$ and freight volume in 2035-2050 will achieve an average annual growth rate of $0.79 \%$. For comparison, China's average annual growth rate of freight volume from 2000 to 2010 was $9.09 \%$, and the average annual growth rate of freight volume from 2010 to 2020 was about $3.8 \%$. Figure 1 shows the changes in the value of each industry's demand for transportation.

From the perspective of structural changes in the proportion of transportation demand by various industries, from 2017 to 2050, almost the proportions of the primary and secondary industries have declined, while the proportions of the tertiary industry have almost increased. This shows that, in the postindustrialization period, the development of the service industry was significantly faster than the development of other industries, which also led to a further slowdown in the growth of freight traffic.

From the statistics of the past years, the ranking of the value of transportation demand by each industry is shown in Figure 2.

As can be seen from the above figure, apart from the transportation industry itself, the largest demand for transportation is the construction industry, chemical industry, metal smelting, and rolling processing industry in order. From the comparison of the three industries, the second industry has the largest demand for transportation, with an average demand of $67.56 \%$, followed by 
TABLE 5: Forecast value of each Industry's demand for transportation in 2050.

\begin{tabular}{|c|c|c|c|c|}
\hline Industry number & $\begin{array}{c}\text { Total output } \\
\text { (unit: ten thousand yuan) }\end{array}$ & $\begin{array}{l}\text { Complete consumption } \\
\text { coefficient for transportation }\end{array}$ & $\begin{array}{l}\text { Value of demand for transportation } \\
\text { (unit: ten thousand yuan) }\end{array}$ & Percentage (\%) \\
\hline 1 & 2305058914.95858 & 0.1038 & 161562882.649893 & 2.32 \\
\hline 2 & 225399239.252031 & 0.0473 & 17175036.81653 & 0.25 \\
\hline 3 & 296358702.504236 & 0.0376 & 9049175.65735843 & 0.13 \\
\hline 4 & 130754716.209892 & 0.0222 & 6484079.06508876 & 0.09 \\
\hline 5 & 309703690.668892 & 0.1044 & 22453457.2200924 & 0.32 \\
\hline 6 & 4993316219.24954 & 0.1070 & 340105785.712392 & 4.88 \\
\hline 7 & 1169877601.05839 & 0.1415 & 117422343.628579 & 1.69 \\
\hline 8 & 1168227930.42133 & 0.1640 & 129998582.75392 & 1.87 \\
\hline 9 & 898528918.228418 & 0.1192 & 74024374.9193083 & 1.06 \\
\hline 10 & 1296795582.07195 & 0.1245 & 111632630.312471 & 1.60 \\
\hline 11 & 1103236675.70768 & 0.1197 & 84897524.7620998 & 1.22 \\
\hline 12 & 6082124100.93906 & 0.1380 & 559648454.680745 & 8.03 \\
\hline 13 & 2962043458.50494 & 0.1397 & 262428339.838558 & 3.77 \\
\hline 14 & 3516241093.09762 & 0.0987 & 266973521.479866 & 3.83 \\
\hline 15 & 1588705051.31154 & 0.1102 & 123006525.792954 & 1.77 \\
\hline 16 & 2334054745.42645 & 0.1144 & 202876346.366929 & 2.91 \\
\hline 17 & 3772776250.86454 & 0.1225 & 308797754.667791 & 4.43 \\
\hline 18 & 1956366422.70817 & 0.1088 & 159468719.375415 & 2.29 \\
\hline 19 & 4072416886.88244 & 0.0959 & 271783708.552732 & 3.90 \\
\hline 20 & 273918886.849786 & 0.0980 & 20990293.5368699 & 0.30 \\
\hline 21 & 69258710.8799772 & 0.1317 & 7903185.38635047 & 0.11 \\
\hline 22 & 190762990 & 0.0681 & 9218409.26 & 0.13 \\
\hline 23 & 1815383914 & 0.0927 & 117675194 & 1.69 \\
\hline 24 & 269735335 & 0.0990 & 14424819 & 0.21 \\
\hline 25 & 75433673.6 & 0.0705 & 3806428.69 & 0.05 \\
\hline 26 & 9443402536 & 0.1151 & 709202296 & 10.18 \\
\hline 27 & 5471472846 & 0.1713 & 562210630 & 8.07 \\
\hline 28 & 811383667 & 0.2225 & 85768156.9 & 1.23 \\
\hline 29 & 4335630503 & 0.0719 & 158565803 & 2.28 \\
\hline 30 & 5650048503 & 0.0729 & 262858125 & 3.77 \\
\hline 31 & 1659109449 & 0.0934 & 98272095.3 & 1.41 \\
\hline 32 & 8406177069 & 0.0663 & 272915377 & 3.92 \\
\hline 33 & 5398007001 & 0.0515 & 132374469 & 1.90 \\
\hline 34 & 6425920047 & 0.1576 & 515839451 & 7.41 \\
\hline 35 & 744685082 & 0.1314 & 49152590 & 0.71 \\
\hline 36 & 3083798855 & 0.1208 & 205911786 & 2.96 \\
\hline 37 & 675704995 & 0.1077 & 39389822.1 & 0.57 \\
\hline 38 & 1377773846 & 0.0521 & 48379471.9 & 0.69 \\
\hline 39 & 1788434989 & 0.0397 & 48525487.5 & 0.70 \\
\hline 40 & 2444382047 & 0.0912 & 132192062 & 1.90 \\
\hline 41 & 888041276 & 0.1044 & 50578115.6 & 0.73 \\
\hline 42 & 3457545322 & 0.0978 & 189436875 & 2.72 \\
\hline
\end{tabular}

the tertiary industry, with an average demand of $29.36 \%$, and, finally, the primary industry, with an average demand of $3.08 \%$.

5.3. Time Series Models. Time series regression is another reasonable method to examine the relationship between time-ordered variables. In recent decades, the freight volume per unit GDP has been declining year by year, which is closely related to the change of industrial structure. The fitting and forecasting trend line is shown in Figure 3 (M2).

Model 2 shows good fitting effect; according to Model 2, China's freight volume will be 77.31 billion tons in 2035 and 87.81 billion tons in 2050 .
The single-equation autoregressive integrated moving average (ARIMA) time series model has also achieved good forecasting results $[81,82]$. The ARIMA model is a model in which forecasted values are obtained by regressing past values of the variable itself and the current value with the error terms of the past values at different lag lengths. The proposed model structure is given in

$$
Y_{t}=C+\alpha_{1} \mathrm{GDP}_{1}+\alpha_{2} \mathrm{GDP}_{2}+\beta Y_{t-1}+\varepsilon,
$$

where $Y_{t}$ represents the freight in million tons in year $t$ and $\mathrm{GDP}_{1}$ represents the difference between the added value of the primary industry this year and the previous year. The remaining variables and parameters are self-explanatory. The fitting results are as follows (M3): 
TABLE 6: 2002-2017 freight demand value and freight volume statistics.

\begin{tabular}{lcc}
\hline Year & Transportation value (unit: ten thousand yuan) & Freight volume (unit: 100 million tons) \\
\hline 2002 & 284916168.9 & 148.34 \\
2005 & 569828620.4 & 186.21 \\
2007 & 698441069 & 227.58 \\
2010 & 1250578926 & 324.18 \\
2012 & 1426917180 & 410.04 \\
2015 & 1976730089 & 417.59 \\
2017 & 2108324779 & 480.49 \\
\hline
\end{tabular}

Data source: China National Bureau of Statistics and the author's calculations.

TABle 7: The fitting effect of different models and the predicted value of freight volume comparison.

\begin{tabular}{ll}
\hline & Unary linear function \\
\hline
\end{tabular}

Data source: China National Bureau of Statistics and the author's calculation, unit: 100 million tons.

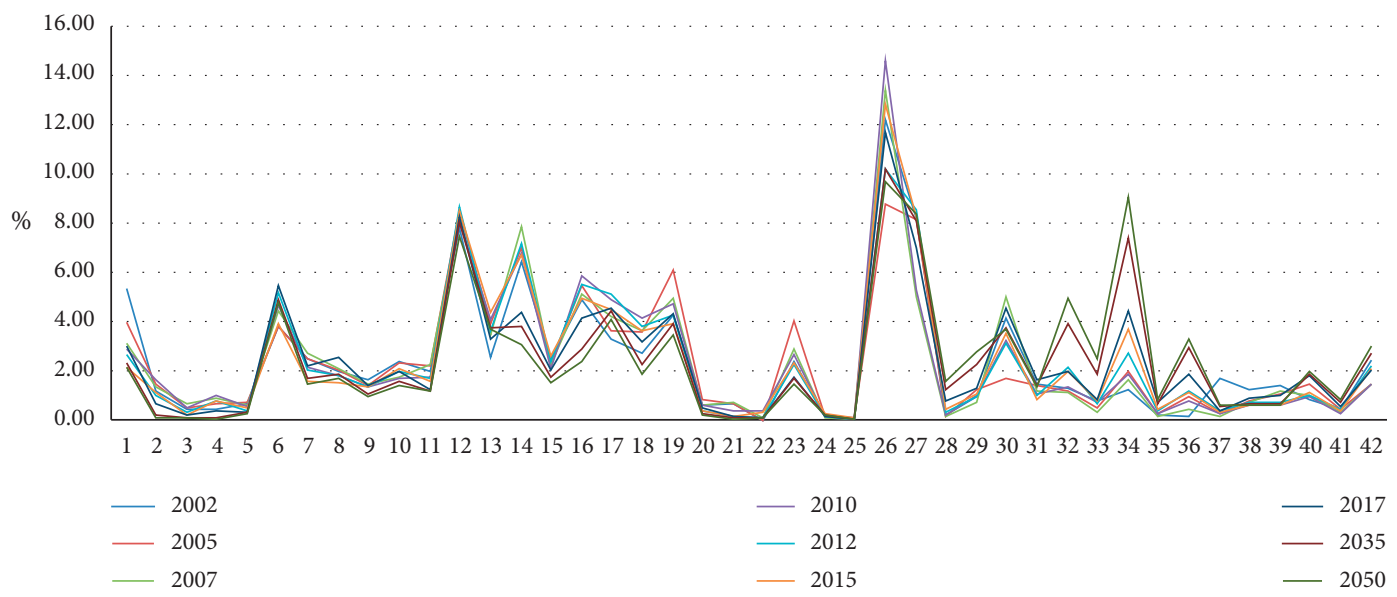

Figure 1: Statistics of changes in the value of transportation demand for various industries in China from 2002 to 2050. Data source: China National Bureau of Statistics and the author's calculation; 1-42 represent the serial numbers of each industry.

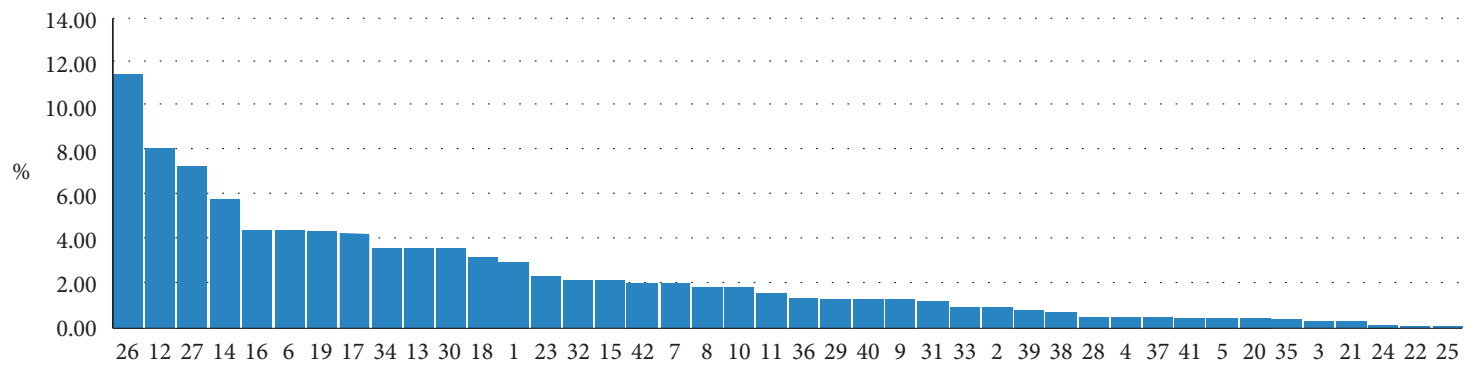

FIGURE 2: Statistics on the average proportion of the demand for transportation by various industries in China from 2002 to 2050 . Data source: China National Bureau of Statistics and the author's calculation. 


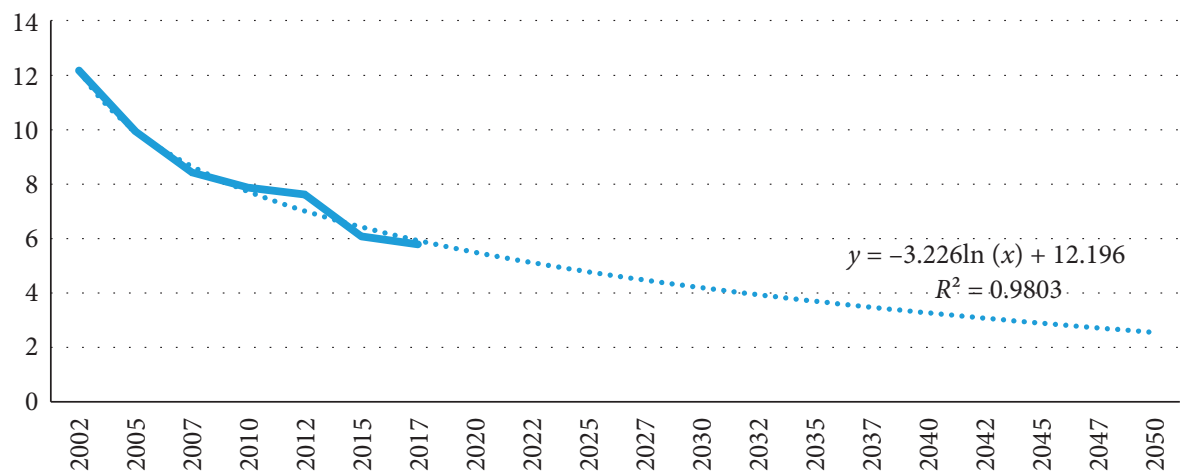

Figure 3: Forecast chart of freight volume per unit GDP. The solid line is the actual freight, and the dotted line is the predicted freight. The ordinate is the freight volume per GDP, and the unit is 100 million tons/trillion yuan.

$$
Y_{t}=-10.072+40.874 \mathrm{GDP}_{1}+9.834 \mathrm{GDP}_{2}+0.976 Y_{t-1}
$$

According to Model 3, China's freight volume will be 65.02 billion tons in 2035 and 79.18 billion tons in 2050 . The errors for univariate time series models vary from about $0.06 \%$ to $7.98 \%$, whereas the error for multivariate time series models lies between $0.13 \%$ and $7.17 \%$ at $95 \%$ confidence level. Multivariate time series model shows better prediction effect and further verifies the accuracy of the regression model.

\section{Numerical Experiments and Analysis}

6.1. Analysis of the Impact of Changes in the Economic Value of Transportation. The complete decomposition model is used to decompose the changes in the economic value of transportation, and the effects of changes in the complete consumption coefficient, changes in industrial structure, and changes in economic aggregates on the economic value of transportation are calculated, respectively. The results are shown in Table 8.

From 2017 to 2035, the economic value of transportation increased to 498,865 billion yuan. From the perspective of industrial structure, the secondary industry has the greatest impact on the incremental value of transportation, accounting for $53.42 \%$, the tertiary industry also has a greater impact, accounting for $44.53 \%$, and the primary industry has the least impact, accounting for $2.05 \%$. From the perspective of influencing factors, the increase in total output has the greatest impact on the changes in the economic value of transportation, accounting for $80.88 \%$, the second is the change in the complete consumption coefficient, accounting for $19.14 \%$, and changes in the industrial structure make transportation the economic value increment decreased by $0.01 \%$.

The increase in the economic value of transportation from 2017 to 2050 was 923,964 billion yuan. From the perspective of industrial structure, the tertiary industry has the greatest impact on the incremental value of transportation, accounting for $49.28 \%$, the secondary industry also has a greater impact, accounting for $48.77 \%$, and the primary industry has the least impact, accounting for $1.95 \%$. From the perspective of influencing factors, the increase in total output has the greatest impact on the changes in the economic value of transportation, accounting for $86.55 \%$, the second is the change in the complete consumption coefficient, accounting for $13.9 \%$, and changes in the industrial structure make transportation economic value increment decreased by $0.45 \%$.

6.2. Analysis of the Impact of Changes in Economic Aggregates on Freight Volume. Because of the uncertainty of total economic growth, two scenarios of faster economic development and slower economic development are considered:

(1) Scenario of relatively rapid economic development: in this scenario, China's economy will develop faster. It will achieve an average annual growth rate of 5\% from 2021-2035 and an average annual growth rate of $3.6 \%$ from 2036-2050. Some institutions and scholars are optimistic about China's development, as shown in Table 9.

(2) Scenario of slower economic development: in the context of slower economic development, China's economic development is slightly lower than the baseline scenario. The average annual growth rate of China's economic development from 2021-2035 will drop to $4.6 \%$ and the average annual growth rate will drop to $3.2 \%$ from $2036-2050$.

According to the previous assumptions for the two scenarios, the logarithmic function is used for prediction, and the calculation results and the comparison with the baseline scenario are shown in Table 10.

Judging from the calculation results of the three scenarios, the difference in economic growth rate has little effect on the forecast results of freight traffic. The degree of economic growth rate affecting freight volume represents the elasticity of GDP to freight traffic. The freight elasticity of the United States has gradually decreased since 1990 and is currently about 0.1-0.2. Germany's freight elasticity has gradually decreased since 1990 and is currently around 0.20.3. Due to the difficulty of economic recovery in Japan, freight elasticity has been in a negative state since 1990 . Judging from the experience of the United States, Germany, and other developed countries, its freight elasticity is 
TABLE 8: Analysis of the impact of changes in the economic value of transportation in 2017-2035.

\begin{tabular}{lcccccc}
\hline & Primary industry & Percentage $(\%)$ & Secondary industry & Percentage (\%) & Tertiary industry & Percentage (\%) \\
\hline $2017-2035$ & & & & & \\
$b_{j q}$ & 64204832.37 & 62.81 & 526237944.4 & 19.75 & 364246875.7 & 16.40 \\
$s_{j q}$ & 74125315.71 & -72.52 & 310055653.5 & -11.63 & 383447076.3 \\
$X_{j q}$ & 112134478.7 & 109.71 & 2448872953 & 91.89 & 1473686908 & 2221380860 \\
$\Delta Q$ & 102213995.3 & 100 & 2665055244 & 100 & 56.34 \\
\hline $2017-2050$ & & & & & 14.43 & 530706763.8 \\
$b_{j q}$ & 103320453.6 & 57.44 & 650215278.5 & -17.52 & 891515068.6 \\
$s_{j q}$ & 143829310.4 & -79.96 & 789279860.7 & 103.09 & 3131520513 \\
$X_{j q}$ & 220394994.6 & 122.52 & 4645078315 & 100 & 4553742346 \\
$\Delta Q$ & 179886137.8 & 100 & 4506013733 & 19.65 & 68.77 \\
\hline
\end{tabular}

Data source. China National Bureau of Statistics and the author's calculation, unit: 10,000 yuan.

TABle 9: Prediction of China's economic growth rate by some institutions and scholars.

\begin{tabular}{lccc}
\hline Research institutions and scholars & $2021-2030$ & $2031-2040$ & \\
\hline Goldman Sachs & 5.7 & 4.4 & 3.6 \\
HSBC & 5.5 & 4.4 & 4.1 \\
Li Shantong, Hou Yongzhi & 5.4 & 4.5 & 3.4 \\
Li Jingwen & 5.4 & 4.9 & 4.3 \\
Xu Xianchun & 5.5 & 4.5 & 3.5 \\
\hline
\end{tabular}

Source: the long-term outlook for the BRICs and N-11 postcrisis; HSBC Global Economics Research Team; Li and Hou [83]; Li [84]; Xu [85]; unit: \%.

TABLE 10: Comparison of China freight volume forecasts under three scenarios.

\begin{tabular}{lcccc}
\hline Scenario & Forecast for 2035 & $\begin{array}{c}2017-2035 \text { average annual } \\
\text { growth rate of } \\
\text { freight traffic (\%) }\end{array}$ & $\begin{array}{c}\text { Forecast for } \\
2050\end{array}$ & $\begin{array}{c}2035-2050 \text { average annual growth } \\
\text { rate of freight traffic (\%) }\end{array}$ \\
\hline Baseline scenario & 644.85 & 1.65 & 725.18 & 0.79 \\
Slow economic development scenario & 639.7 & 1.60 & 719.36 & 0.79 \\
Faster economic development scenario & 649.99 & 1.69 & 739.44 & 0.86 \\
\hline
\end{tabular}

Data source: author's calculation, forecast unit: 100 million tons.

between $0.1-0.3$, which shows that the impact of economic aggregate growth on freight volume is gradually decreasing.

\subsection{Analysis of the Impact of Industrial Structure Changes on} Freight Traffic. In the late industrialization and postindustrialization period, the decline in freight volume growth was mainly caused by the upgrading of industrial structure. In this stage of industrialization, the proportion of the service industry will increase from $50 \%$ to about $70 \%-80 \%$. The entire national economy is dominated by the service economy and information economy, so the growth rate of freight volume is limited.

To sort out the upgrading of China's industrial structure, its evolutionary structure over the years and the structure forecast for 2035 and 2050 are shown in Figure 4.

From the perspective of future changes in the total output structure of the industry, the primary industry has the largest decline, from $4.88 \%$ in 2017 to $2.2 \%$ in 2050 , and the secondary industry has all declined to vary degrees.
Among them, the coal industry, petroleum industry, and metal mining accounted for the largest decline, with $77.9 \%$, $45.14 \%$, and $75.74 \%$, respectively. The proportion of the accommodation and catering industry in the tertiary industry dropped slightly by 0.1 percentage point, and the rest increased to varying degrees. Among them, the financial industry rose the most, from $4.18 \%$ in 2017 to $8.01 \%$ in 2050 .

By 2050, China's three industrial structures based on total output will account for $2.2: 47.66: 50.14$, respectively. The structure evolution of the three industries is shown in Figure 5 .

To compare the impact of industrial structure on transportation, consider the change in freight volume when only changing the industrial structure with the total economic aggregate, and the complete consumption coefficient is unchanged. Assuming that the industrial structure of 2017 is maintained in 2035 and 2050 and that the demand for freight and passenger transportation from agriculture and industry is $8: 2$ and the demand for freight and passenger 


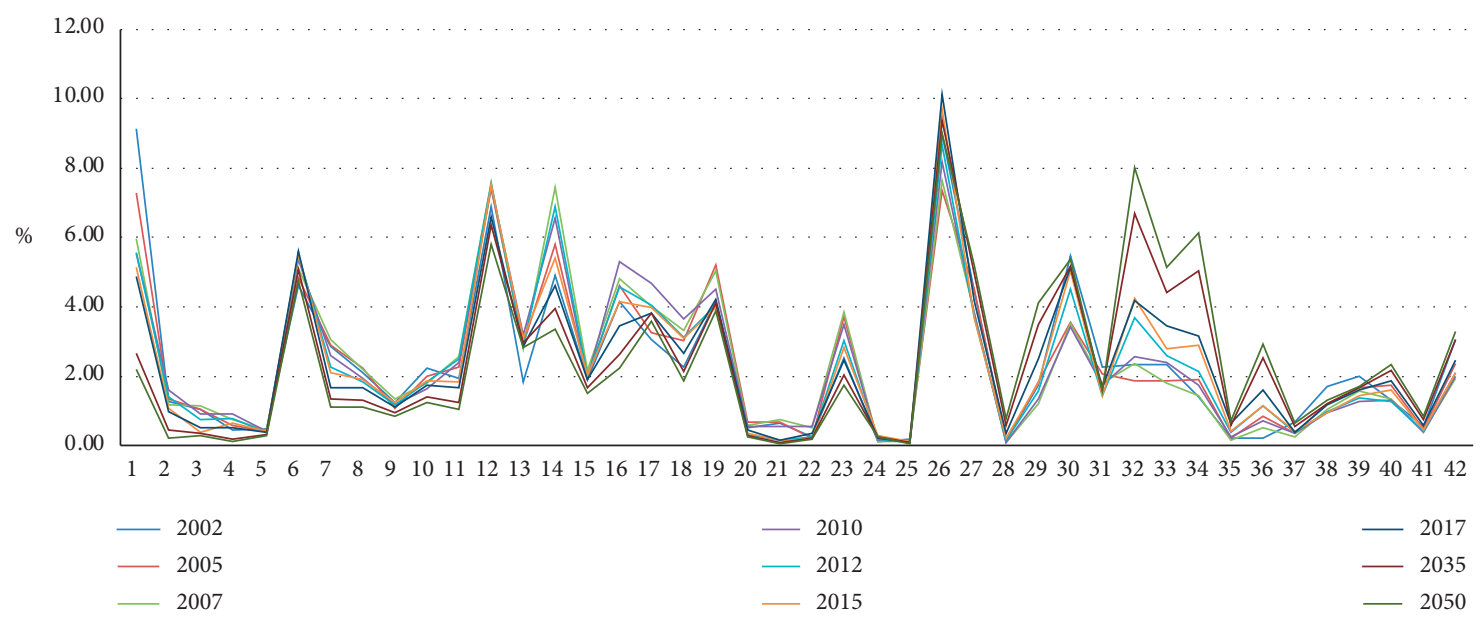

Figure 4: The evolution of China's industrial structure based on total output from 2002 to 2050. Data source: China National Bureau of Statistics and the author's calculation; 1-42 represent the serial numbers of each industry.

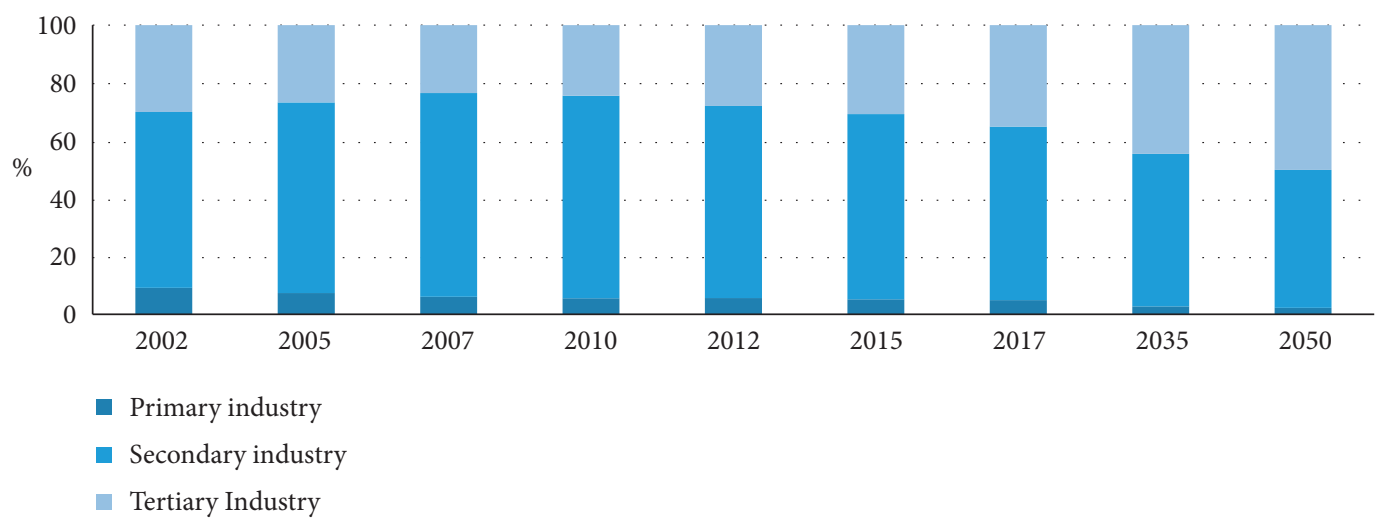

Figure 5: The evolution of China's three industrial structures based on total output. Data source: China National Bureau of Statistics and the author's calculation.

transportation from the service industry is $2: 8$, then the forecast value of freight volume in 2035 and 2050 is shown in Table 11.

When the industrial structure of 2017 is maintained, the predicted value of freight volume in 2035 and 2050 is $9.49 \%$ and $16.22 \%$ higher than the baseline value, respectively. This shows that the upgrading of the industrial structure has slowed down the growth rate of freight traffic. In the forecast of freight traffic, the importance of industrial structure exceeds that of economic aggregate.

6.4. Analysis of the Impact of Changes in the Complete Consumption Coefficient on Freight Traffic. The impact of technological progress on transportation is mainly reflected in three aspects: industrial upgrading has led to a decline in the proportion of traditional industrial added value such as coal, petroleum, and steel and an increase in the proportion of high-end industries such as computers, precision instruments, and equipment manufacturing. The improvement of technology makes the industry's consumption rate of coal, oil, natural gas, and other energy sources gradually drop; the transportation capacity and service level are improved. Reflected in the input-output table, it is mainly reflected in the change of the complete consumption coefficient.

The complete consumption factor is affected by two factors. One is the direct consumption coefficient, which represents the relationship between the demand of the industry and another industry and reflects the degree of energy consumption; the second is the indirect consumption coefficient, which represents the direct and indirect demand relationship between the industry and other industries and reflects the depth and breadth of the industrial chain. Figure 6 shows the direct consumption of transportation by various industries.

From the perspective of the direct consumption coefficient, the largest direct consumption of transportation is the transportation, postal, and nonmetallic mining and processing industries. Because the direct consumption coefficient cannot reflect the industry's complete demand for transportation, it is necessary to calculate the complete consumption coefficient. The complete consumption coefficient is shown in Figure 7. 
TABLE 11: Comparison of the predicted value of freight volume with the baseline predicted value when the industrial structure remains unchanged.

\begin{tabular}{lcccc}
\hline & & $\begin{array}{c}\text { Forecast for 2035 } \\
\text { Predicted value when the industrial } \\
\text { structure is unchanged }\end{array}$ & Baseline forecast & $\begin{array}{c}\text { Forecast for 2050 } \\
\text { Predicted value when the } \\
\text { industrial structure is unchanged }\end{array}$ \\
\hline Primary industry & 25.85 & 47.3 & 25.57 & 56.75 \\
Secondary industry & 510.88 & 574.58 & 553.92 & 686.03 \\
Tertiary industry & 107.85 & 83.83 & 145.69 & 99.99 \\
Total freight volume & 644.58 & 705.72 & 725.18 & 842.77 \\
\hline
\end{tabular}

Data source: China's National Bureau of Statistics and the author's calculation, freight volume unit: 100 million tons.

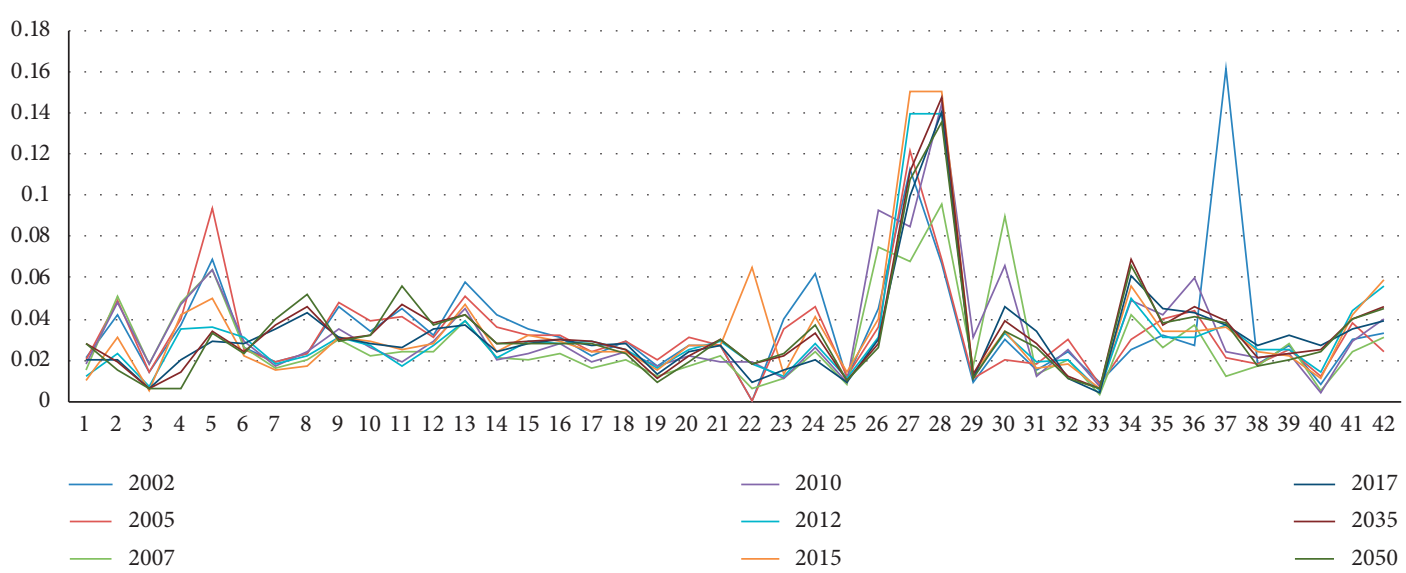

Figure 6: Statistics of direct consumption coefficients over the years and forecast values in 2035 and 2050. Data source: China's National Bureau of Statistics and the author's calculation; 1-42 are the industry numbers.

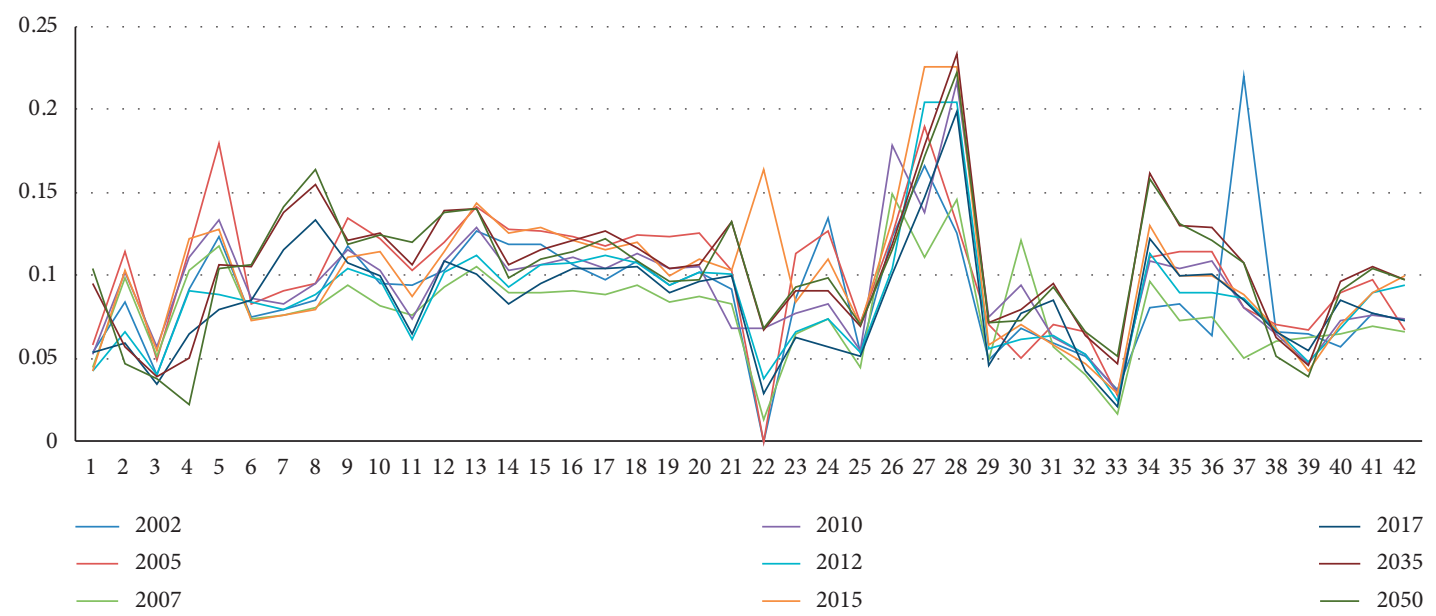

Figure 7: Statistics of complete consumption coefficient over the years and forecast values in 2035 and 2050. Data source: China's National Bureau of Statistics and the author's calculation; 1-42 are the industry numbers.

From the perspective of the full consumption coefficient, the postal, transportation, and construction industries have the greatest demand for transportation. From the perspective of the changes in the complete consumption coefficient and the direct consumption coefficient, except for petroleum, coking products, and nuclear fuel processing industries, the coefficient of variation of the complete consumption coefficient of other industries exceeds that of the direct consumption coefficient. This indicates that the industry chain will further deepen from now on, which also leads to a further increase in the complete consumption coefficient.

Assuming that the full consumption coefficient of 2017 is maintained in 2035 and 2050, the forecast value of freight volume in 2035 and 2050 is shown in Table 12.

When the complete consumption coefficient remains unchanged, the predicted value of freight volume in 2035 
TABLE 12: Comparison of the predicted value of freight volume with the baseline predicted value when the complete consumption coefficient remains unchanged.

\begin{tabular}{|c|c|c|c|c|}
\hline & \multicolumn{2}{|r|}{ Forecast for 2035} & \multicolumn{2}{|r|}{ Forecast for 2050} \\
\hline & $\begin{array}{l}\text { Baseline } \\
\text { forecast }\end{array}$ & $\begin{array}{l}\text { Predicted value when the } \\
\text { complete consumption coefficient does } \\
\text { not change }\end{array}$ & $\begin{array}{l}\text { Baseline } \\
\text { forecast }\end{array}$ & $\begin{array}{l}\text { Predicted value when the } \\
\text { complete consumption coefficient does } \\
\text { not change }\end{array}$ \\
\hline Primary industry & 25.85 & 18.14 & 25.57 & 13.3 \\
\hline $\begin{array}{l}\text { Secondary } \\
\text { industry }\end{array}$ & 510.88 & 317.02 & 553.92 & 459.76 \\
\hline Tertiary industry & 107.85 & 45.25 & 145.69 & 116.55 \\
\hline $\begin{array}{l}\text { Total freight } \\
\text { volume }\end{array}$ & 644.58 & 380.41 & 725.18 & 589.6 \\
\hline
\end{tabular}

Data source: China's National Bureau of Statistics and the author's calculation.

and 2050 will decrease by $40.98 \%$ and $18.7 \%$, respectively. This shows that the change in the complete consumption coefficient is the main reason for the change in freight traffic.

\section{Conclusion}

This paper constructs a freight value and freight volume analysis model based on the input-output method and predicts the development trend of China's freight volume and uses a complete decomposition model to analyze the factors affecting freight value and freight volume. The study reached the following conclusions:

(1) The growth rate of China's freight volume will gradually decline, with an average annual growth rate of $1.65 \%$ from 2017 to 2035 and an average annual growth rate of $0.79 \%$ from 2035 to 2050 . Research shows that China freight volume in 2035 is 64.458 billion tons and 72.518 billion tons in 2050 .

(2) From the perspective of industrial structure, the tertiary industry has the greatest impact on the incremental value of transportation, accounting for $49.28 \%$, the secondary industry also has a greater impact, accounting for $48.77 \%$, and the primary industry has the least impact, accounting for 1.95\%. From the perspective of influencing factors, the increase in total output has the greatest impact on the changes in the economic value of transportation, accounting for $86.55 \%$, the second is the change in the complete consumption coefficient, accounting for $13.9 \%$, and changes in the industrial structure make transportation economic value decreased by $0.45 \%$.

(3) When the industrial structure of 2017 is maintained, the predicted value of freight volume in 2035 and 2050 is $9.49 \%$ and $16.22 \%$ higher than the baseline value, respectively. This shows that the upgrading of the industrial structure has slowed down the growth rate of freight traffic. When the complete consumption coefficient remains unchanged, the predicted freight volume in 2035 and 2050 will decrease by $40.98 \%$ and $18.7 \%$, respectively. This shows that the change in the complete consumption coefficient is the main reason for the change in freight traffic. The change in economic aggregate has a limited impact on freight traffic, and the upgrading of industrial structure will cause a decline in freight traffic. The increase in the full consumption coefficient indicates that the integration between industries is improving, which means that the accuracy of freight forecasting through industry division will decrease.

As this paper is compared with the previous models, the main differences of this paper are as follows: (1) this paper further subdivides the industry, dividing the industry sector into 42 sectors, which is more refined than the previous three industry divisions and can better reflect the relationship between different industries and freight demand; (2) in the past, factor analysis often used methods such as multiple regression and cluster analysis, which could not reflect the importance and relevance of factors. This paper uses a complete decomposition model to analyze the influencing factors of freight volume, which can effectively analyze the relationship between the influencing factors; (3) this paper combines gray forecasting and input-output analysis, which can analyze the factors of future freight demand changes, which is more practical and referential than the previous analysis of the current status of influencing factors.

Due to the lack of freight data of related industries, this paper predicts the freight volume from the overall freight value and industry GDP, and the accuracy of the forecast needs to be tested. Future research can further analyze the influence relationship between different industries based on this model, use feature analysis to further optimize the industrial structure, and use this model in conjunction with the OD tables for transportation planning research. Further statistics on the freight volume data of related industries and the use of the fusion of multiple models to make predictions can improve the accuracy of freight volume forecasts, which is the direction of future research.

\section{Data Availability}

The data used to support the findings of this study are included in the paper.

\section{Conflicts of Interest}

The authors declare that they have no conflicts of interest. 


\section{Acknowledgments}

This research was supported by Zhejiang Provincial Natural Science Foundation (project no. LY20G010009).

\section{References}

[1] W. B. Allen, "The demand for freight transportation: a micro approach," Transportation Research, vol. 11, no. 1, pp. 9-14, 1977.

[2] C. M. Winston, "The demand for freight transportation: models and applications," Transportation Research, vol. 17A, no. 6, pp. 419-427, 1983.

[3] D. Banister and D. Stead, "Reducing transport intensity," EJTIR, vol. 2-4, pp. 161-178, 2002.

[4] E. Bennathan, J. Fraser, and L. S. Thompson, "What determines demand for freight transport? The world bank, infrastructure and urban development department," 1992, http://www.worldbank.org/transport/publicat/b31.pdf.

[5] A. Alises and J. M. Vassallo, "The impact of the structure of the economy on the evolution of road freight transport: a macro analysis from an input-output approach," Transportation Research Procedia, vol. 14, pp. 2870-2879, 2016.

[6] Y. Zhang, Y. Gao, Y. Xie, and S. Qi, "Analysis of influencing factors of integrated freight transport volume based on gray markov model," in Proceedings of the Green Intelligent Transportation Systems (GITSS 2017), vol. 503, Changchun, China, 2019.

[7] P. Wang, X. Zhang, B. Han et al., "Prediction model for railway freight volume with GCA-genetic algorithm-generalized neural network: empirical analysis of China," Cluster Computing, vol. 22, pp. 4239-4248, 2019.

[8] Q. Sun, X. Guo, W. Jiang, H. Ding, T. Li, and X. Xu, "Exploring the node importance and its influencing factors in the railway freight transportation network in China," Journal of Advanced Transportation, vol. 2019, Article ID 1493206, 16 pages, 2019.

[9] A. K. Bhunia, A. A. Shaikh, V. Dhaka et al., "An application of genetic algorithm and PSO in an inventory model for single deteriorating item with variable demand dependent on marketing strategy and displayed stock level," Scientia Iranica, vol. 25, no. 3, pp. 1641-1655, 2018.

[10] M. Gilotra, S. Pareek, M. Mittal, and V. Dhaka, "Effect of carbon emission and human errors on a two-echelon supply chain under permissible delay in payments," International Journal of Mathematical, Engineering and Management Sciences, vol. 5, no. 2, pp. 225-236, 2020.

[11] Aastha, S. Pareek, and M. Mittal, "Non instantaneous deteriorating inventory model under credit financing when demand depends on promotion and selling price," in Proceedings of the 2020 8th International Conference on Reliability, Infocom Technologies and Optimization (Trends and Future Directions) (ICRITO), IEEE, Noida, India, 2020.

[12] S. Pareek, "Two storage inventory model for non-instantaneous deteriorating item with stochastic demand under credit financing policy," in Proceedings of the 2020 8th International Conference on Reliability, Infocom Technologies and Optimization (Trends and Future Directions) (ICRITO), IEEE, Noida, India, 2020.

[13] Aastha, S. Pareek, M. Mittal, and L. Cárdenas-Barrón, "Impact of imperfect quality items on inventory management for two warehouses with shortages," International Journal of Mathematical,Engineering and Management Sciences, vol. 5, no. 5, pp. 869-885, 2020.
[14] B. Sarkar, B. K. Dey, M. Sarkar, S. Hur, B. Mandal, and V. Dhaka, "Optimal replenishment decision for retailers with variable demand for deteriorating products under a tradecredit policy," RAIRO-Operations Research, vol. 54, no. 6, pp. 1685-1701, 2020.

[15] P. Krata, "Implementation of gravity model to estimation of transportation market shares," Archives of Transport, vol. 22, pp. 83-96, 2010.

[16] D. Pyza, "Multi-criteria evaluation of transportation systems in supply chains," Archives of Transport, vol. 23, pp. 47-65, 2011.

[17] L. Tavasszy and G. De Jong, Modelling Freight Transport, Elsevier, Amsterdam, Netherlands, 2014.

[18] M. Xiao and C. Li, "Fuzzy regression prediction and application based on multi-dimensional factors of freight volume," IOP Conference Series: Earth Environmental Sciences, vol. 108, Article ID 032071, 2018.

[19] T. R. Lakshmanan, "The broader economic consequences of transport infrastructure investments," Journal of Transport Geography, vol. 19, no. 1, pp. 1-12, 2011.

[20] M.-K. Lee and S.-H. Yoo, "The role of transportation sectors in the Korean national economy: an input-output analysis," Transportation Research Part A: Policy and Practice, vol. 93, pp. 13-22, 2016.

[21] O. Ivanova, "Modelling inter-regional freight demand with input-output, gravity and SCGE methodologies," Modelling Freight Transport, pp. 13-42, 2014.

[22] W. Robert, R. Douglas, V. J. Carlos, and National Academies of Sciences, Engineering, and Medicine, Identification and Evaluation of Freight Demand Factors, The National Academies Press, Washington, DC, USA, 2012.

[23] J. T. Fite, G. Don Taylor, J. S. Usher, J. R. English, and J. N. Roberts, "Forecasting freight demand using economic indices," International Journal of Physical Distribution \& Logistics Management, vol. 32, no. 4, pp. 299-308, 2002.

[24] P. Agnolucci and D. Bonilla, "UK freight demand: elasticities and decoupling," Journal of Transport Economics \& Policy, vol. 43, no. 3, pp. 317-344, 2009.

[25] H. Wang, K. Jang, and C. Chan, "Analysis and multi-level modeling of truck freight demand," in Proceedings of the SHRP2 Innovations in Freight Demand Modeling and Data Symposium, Washington, DC, USA, 2010.

[26] M. Short, L. T. Elasticities, F. N. G. Andersson et al., "Swedish freight demand: short, medium, and long-term elasticities," Journal of Transport Economics and Policy, vol. 46, 2012.

[27] A. Wijeweera, H. To, and M. Charles, "An empirical analysis of Australian freight rail demand," Economic Analysis and Policy, vol. 44, no. 1, pp. 21-29, 2014.

[28] A. Alises and J. M. Vassallo, "Comparison of road freight transport trends in Europe. Coupling and decoupling factors from an input-output structural decomposition analysis," Transportation Research Part A: Policy and Practice, vol. 82, pp. 141-157, 2015.

[29] G. R. Patil and P. K. Sahu, "Estimation of freight demand at Mumbai port using regression and time series models," KSCE Journal of Civil Engineering, vol. 20, no. 5, pp. 2022-2032, 2016.

[30] H. Wang, J. Han, M. Su, S. Wan, and Z. Zhang, "The relationship between freight transport and economic development: a case study of China," Research in Transportation Economics, vol. 85, Article ID 100885, 2020.

[31] M. Z. Khan and F. N. Khan, "Estimating the demand for rail freight transport in Pakistan: a time series analysis," Journal of 
Rail Transport Planning \& Management, vol. 14, Article ID 100176, 2020.

[32] J. F. Dewey, D. Denslow, D. Lenze et al., The Response of Railroad and Truck Freight Shipments to Optimal Excess Capacity Subsidies and Externality Taxes: An Empirical Study of Florida's Surface Freight Transportation Market, University of Florida, Gainesville, FL, USA, 2002.

[33] J. Holguin-Veras, "Revealed preference analysis of commercial vehicle choice process," Journal of Transportation Engineering, vol. 128, no. 4, p. 336, 2002.

[34] K. S. Kim, "Inherent random heterogeneity logit model for stated preference freight mode choice," Journal of Korean Society of Transportation, vol. 20, no. 3, pp. 1-10, 2002.

[35] O. Norojono and W. Young, "A stated preference freight mode choice model," Transportation Planning and Technology, vol. 26, p. 2, 2003.

[36] K. Train and W. Wilson, "Spatial demand decisions in the pacific northwest: mode choices and market areas," Transportation Research Record, vol. 1963, 2006.

[37] K. Arunotayanun and J. Polak, "Taste heterogeneity in freight shippers' mode choice behaviour," in Proceedings of the 2007 Annual Meeting of the Transportation Research Board, Washington, DC, USA, 2007.

[38] Z. Patterson, G. O. Ewing, and M. Haider, "Shipper preferences suggest strong mistrust of rail," Transportation Research Record: Journal of the Transportation Research Board, vol. 2008, no. 1, pp. 67-74, 2007.

[39] G. De Jong, "Discrete mode and discrete or continuous shipment size choice in freight transport in sweden," in Proceedings of the 2009 European Transport Conference, Noordwijk, Netherlands, 2009.

[40] R. Cavalcante and M. J. Roorda, "A disaggregate urban shipment size/vehicle-type choice model," in Proceedings of the 2010 Annual Meeting of the Transportation Research Board, Washington, DC, USA, 2010.

[41] E. Windisch, G. de Jong, R. van Nes, and A. Hoogendoorn, “A disaggregate freight transport model of transport chain and shipment size choice," in Proceedings of the 2010 European Transport Conference, Glasgow, UK, 2010.

[42] A. Samimi, K. Kawamura, and A. Mohammadian, "A behavioral analysis of freight mode choice decisions," Transportation Planning and Technology, vol. 34, no. 8, pp. 857-869, 2011.

[43] R. Lloret-Batlle and F. Combes, "Estimation of an inventory theoretical model of mode choice in freight transport," Transportation Research Record: Journal of the Transportation Research Board, vol. 2378, no. 1, pp. 13-21, 2013.

[44] Z. Pourabdollahi, B. Karimi, and A. Mohammadian, "Joint model of freight mode and shipment size choice," Transportation Research Record: Journal of the Transportation Research Board, vol. 2378, no. 1, pp. 84-91, 2013.

[45] M. Abate and G. de Jong, "The optimal shipment size and truck size choice-the allocation of trucks across hauls," Transportation Research Part A: Policy and Practice, vol. 59, pp. 262-277, 2014.

[46] M. Stinson, Z. Pourabdollahi, V. Livshits, K. Jeon, S. Nippani, and $\mathrm{H}$. Zhu, "A joint model of mode and shipment size choice using the first generation of commodity flow survey public use microdata," International Journal of Transportation Science and Technology, vol. 6, no. 4, pp. 330-343, 2017.

[47] C. Román, A. I. Arencibia, and M. Feo-Valero, "A latent class model with attribute cut-offs to analyze modal choice for freight transport," Transportation Research Part A: Policy and Practice, vol. 102, pp. 212-227, 2017.
[48] H.-C. Kim, A. Nicholson, and D. Kusumastuti, "Analysing freight shippers' mode choice preference heterogeneity using latent class modelling," Transportation Research Procedia, vol. 25, pp. 1109-1125, 2017.

[49] A. M. Larranaga, J. Arellana, and L. A. Senna, "Encouraging intermodality: a stated preference analysis of freight mode choice in Rio Grande do Sul," Transportation Research Part A: Policy and Practice, vol. 102, pp. 202-211, 2017.

[50] M. Abate, I. Vierth, R. Karlsson, G. de Jong, and J. Baak, "A disaggregate stochastic freight transport model for Sweden," Transportation, vol. 46, no. 3, pp. 671-696, 2019.

[51] A. F. Jensen, M. Thorhauge, G. de Jong et al., "A disaggregate freight transport chain choice model for Europe," Transportation Research Part E: Logistics and Transportation Review, vol. 121, pp. 43-62, 2019.

[52] N. Keya, S. Anowar, and N. Eluru, "Joint model of freight mode choice and shipment size: a copula-based random regret minimization framework," Transportation Research Part E: Logistics and Transportation Review, vol. 125, pp. 97-115, 2019.

[53] A. Comi and A. Polimeni, "Assessing the potential of short sea shipping and the benefits in terms of external costs: application to the mediterranean basin," Sustainability, vol. 12, no. 13 , p. $5383,2020$.

[54] J. Oosterhaven, Interregional Input-Output Analysis and Dutch Re- gional Policy Problems, Gower, Aldershot, UK, 1981.

[55] W. Beyers, "Structural change in interregional input-output models: form and regional economic development implications," in Frontiers of Input-Output Analysis, R. E. Miller, K. R. Polenske, and A. Z. Rose, Eds., pp. 180-192, Oxford, New York, NY, USA, 1989.

[56] G. Shao and R. E. Miller, "Demand-side and supply-side commodity-industry multiregional input-output models and spatial linkages in the US regional economy," Economic Systems Research, vol. 2, no. 4, pp. 385-406, 1990.

[57] P. Beaumont, ECESIS: An Interregional Economic-Demographic Model of the United States, Routledge, London, UK, 1989.

[58] T. Lienesch and J. R. Kort, "The NRIESII multiregional economic model of the United States," International Regional Science Review, vol. 14, pp. 255-274, 1992.

[59] W. Isard, "Interregional and regional input-output analysis: a model of a space-economy," The Review of Economics and Statistics, vol. 33, no. 4, p. 318, 1951.

[60] L. N. Moses, "The stability of interregional trading patterns and input-output analysis," American Economic Review, vol. 45, pp. 803-832, 1955.

[61] V. Marzano and A. Papola, "Modelling freight demand at a national level: theoretical development and application to Italian demand," in Proceedings of 2004 ETC Conference, Strasbourg, France, 2004.

[62] R. Miller, Input-Output Analysis: Foundations and Extensions, Palgrave Macmillan UK, London, UK, 1985.

[63] N. Voigtlaender, A Dynamic Input-Output Model to Project U.S. Freight Transportation Demand, Massachusetts Institute of Technology, Department of Civil and Environmental Engineering, Cambridge, MA, USA, 2002.

[64] S. J. Rey, "Integrated regional econometric+input-output modeling: issues and opportunities," Papers in Regional Science, vol. 79, no. 3, pp. 271-292, 2000.

[65] J. H. Havenga and Z. P. Simpson, "National freight demand modelling: a tool for macrologistics management," The 
International Journal of Logistics Management, vol. 29, no. 4, pp. 1171-1195, 2018.

[66] A. Daugherty, "Freight transport demand revisited: a microeconomic view of multimodal, multicharacteristics service uncertainty and the demand for freight transport," Transportation Research, vol. 13B, pp. 281-288, 1979.

[67] G. Picard and S. Nguyen, "Estimation of interregional freight flows using input-output analysis," in Freight Transport Planning and Logistics, L. Bianco and A. La Bella, Eds., Springer-Verlag, Berlin, Germany, 1987.

[68] M. Mazzarino, "Modelling freight transport demand: a survey," Trasporti Europei, vol. 5, pp. 1-55, 1997.

[69] A. Regan and R. A. Garrido, "Modeling freight demand and shipper behavior: state of the art and future directions," in The Leading Edge of Travel Behaviour Research, D. Hensher, Ed., Pergamon Press, Oxford, UK, 2002.

[70] J. Holguín-Veras, M. Jaller, I. Sanchez-Diaz et al., "Freight trip generation and land use," National Cooperative Freight Research Program, vol. 19, 2012.

[71] J. Holguín-Veras, M. Jaller, I. Sanchez-Diaz et al., "NCFRP 25 freight generation and freight generation models database," 2012, http://transp.rpi.edu/\%7ENCFRP25/FTG-Database.rar.

[72] O. v. d. Riet, G. C. de Jong, and W. Walker, "Drivers of freight transport demand and their policy implications," in Building Blocks for Sustainable Development, A. Perrels and M. LeeGosselin, Eds., pp. 73-102, Emerald, Bingley, UK, 2008.

[73] G. C. Jong and M. E. Ben-Akiva, "Transportation and logistics in supply chains," in The Handbook of Technology Management, H. Bidgoli, Ed., pp. 146-158, John Wiley \& Sons, New York, NY, USA, 2010.

[74] M. Castro-Neto, Y.-S. Jeong, M.-K. Jeong, and L. D. Han, "Online-SVR for short-term traffic flow prediction under typical and atypical traffic conditions," Expert Systems with Applications, vol. 36, no. 3, pp. 6164-6173, 2009.

[75] H. K. Chen, "Supernetworks for combined travel choice models," The Open Transportation Journal, vol. 5, no. 11, pp. 92-104, 2011

[76] J. Ahn, E. Ko, and E. Y. Kim, "Highway traffic flow prediction using support vector regression and Bayesian classifier," in Proceedings of the 2016 International Conference on Big Data and Smart Computing, Hong Kong, China, 2016.

[77] R. A. Garrido and H. S. Mahmassani, "Forecasting freight transportation demand with the space-time multinomial probit model," Transportation Research Part B: Methodological, vol. 34, no. 5, pp. 403-418, 2000.

[78] A. Pompigna and R. Mauro, "Input/output models for freight transport demand: a macro approach to traffic analysis for a freight corridor," Archives of Transport, vol. 54, no. 2, pp. 21-42, 2020.

[79] X. Wang, "Dynamic prediction of equal-dimensional gray numbers with recursive compensation," Journal of Huazhong University of Science and Technology, vol. 4, pp. 9-16, 1989.

[80] W. E. Deming and F. F. Stephan, "On a least squares adjustment of a sampled frequency table when the expected marginal totals are known," Annals of Mathematical Statistics, vol. 11, no. 4, pp. 427-444, 1940.

[81] P. M. Schulze and A. Prinz, "Forecasting container transshipment in Germany," Applied Economics, vol. 41, no. 22, pp. 2809-2815, 2009.

[82] G. E. P. Box, G. M. Jenkins, G. C. Reinsel et al., Time Series Analysis: Forecasting and Control, John Wiley \& Sons, Hoboken, NJ, USA, 2015.
[83] S. Li and Y. Hou, "China's economic growth and development forecast from 2021 to 2050," China Industrial Economic Development, no. 6, pp. 1-2, 2003.

[84] J Li, "Long-term forecast of China's economy in the 21st century (2000 2050)," Metallurgical Economics and Management, no. 3, pp. 4-7, 2000.

[85] X. Xu, "China's future economic growth and its international economic status prospects," Economic Research, no. 3, pp. 27-35, 2002. 